\title{
Correction to: New Topical Therapies for Psoriasis
}

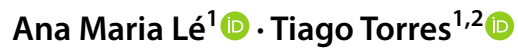

Published online: 14 December 2021

(c) Springer Nature Switzerland AG 2021

\section{Correction to: American Journal of Clinical Dermatology https://doi.org/10.1007/s40257-021-00649-w}

At several places in the manuscript, taparinof was mistakenly referred to as an aryl hydrocarbon receptor inhibitor; whereas, taparinof is an aryl hydrocarbon receptor modulating agent.

This error was made in the following four locations:

Abstract. Fourth sentence.

Key Points. Second Key Point.

Section 3. Heading.

Section 8. Discussion, fifth paragraph, first sentence.

The original article has been corrected.

The original article can be found online at https://doi.org/10.1007/ s40257-021-00649-w.

Tiago Torres

torres.tiago@outlook.com

1 Department of Dermatology, Centro Hospitalar Universitário do Porto, Centro Hospitalar do Porto, Edifício das Consultas Externas, Ex. CICAP, Rua D. Manuel II, s/n, 4100 Porto, Portugal

2 Instituto de Ciências Biomédicas Abel Salazar, University of Porto, Porto, Portugal 